\title{
Reflexión-meditación sobre Monseñor Romero
}

\author{
Jon Sobrino \\ Centro Monseñor Romero \\ San Salvador, El Salvador
}

Monseñor pasó haciendo el bien y sanando a los poseídos por el Diablo, porque Dios estaba con él. Fue colgado de un madero y Dios le resucitó.

Este 15 de agosto, Monseñor Romero hubiera cumplido 100 años. En su recuerdo, publico este artículo sobre su persona y obra. Y añado la carta que Ignacio Ellacuría le escribió desde Madrid, el 9 de abril de 1977, poco después del asesinato del padre Rutilio Grande. La carta expresa magníficamente quién fue Monseñor Romero, para Ellacuría.

Desde su asesinato, el 24 de marzo de 1980, escribo sobre su compromiso con la justicia y los pobres. Por eso, el lector comprenderá que nada muy nuevo puedo decir. Quizás alguna reflexión con ocasión de su beatificación y canonización, más ideas y algunos fragmentos de textos ya publicados. Y enmarco todo ello en la siguiente tesis: En sus tres años como arzobispo de San Salvador, Monseñor Romero se pareció a Jesús de Nazaret. Es lo que digo en el epígrafe.

Ese parecido con Jesús tiene una dimensión de totalidad. Así ha sido reconocido por personas que conocieron de cerca a Monseñor, y lo han hecho desde una conceptualización propia y específica. Basaré mi texto en dos de esas formulaciones que para mí, cada una a su manera, recogen lo fundamental: "Monseñor Romero, durante tres años, se pareció a Jesús de Nazaret". La primera es de un campesino: "Monseñor Romero dijo la verdad. Nos defendió a nosotros, de pobres. Y por eso, lo mataron". La segunda es de Ignacio Ellacuría, en el funeral de la UCA: "Con Monseñor Romero, Dios pasó por El Salvador". 


\section{Las palabras del campesino}

\subsection{Monseñor Romero dijo la verdad}

Así comenzó el campesino. Es parte del equivalente de lo que dijo Pedro: "Jesús pasó haciendo el bien". El decir la verdad lo configuró. Monseñor fue decidor de la verdad, estuvo poseído por ella y la dijo con pathos. Cuando la realidad era buena noticia para los pobres, Monseñor decía la verdad como evangelio, con exultación. Cuando la realidad era opresión y represión, crueldad y muerte, especialmente para los pobres, Monseñor decía la verdad como denuncia y desenmascaramiento. Empapado de la verdad, Monseñor fue evangelizador entrañable y profeta insobornable.

Decir que Mons. Romero fue "decidor" de la verdad puede parecer muy abstracto, y poca cosa en comparación con otras cosas que hizo. Pero por ahí comenzó el campesino, y por buenas razones. "Decir" presuponía estar en contacto inmediato con la realidad exterior en que vivía y con la realidad que llevaba en su interior. "Decir" era, para Mons. Romero, "ser" en total profundidad.

Como "decidor de la verdad", Mons. Romero emitió juicios sobre la realidad, toda ella. Dejó que la realidad tomara la palabra (Karl Rahner). Y fue consecuentemente honrado, haciendo pública esa palabra que pronunciaba la misma realidad. En mi opinión, aquí está la raíz última del impacto de la palabra de Monseñor. Dado el lamentable estado en el que entonces estaba la verdad en el país, el impacto fue inmenso. Como inmenso lo sería hoy si las democracias de Estados Unidos y la Unión Europea, si los mundos globalizados, si las instituciones eclesiásticas y religiosas, dejasen que la realidad tomara la palabra y dijese su verdad. Algunos podrán atenuar este juicio afirmando, con razón, que algo ha mejorado la libertad de expresión, lo cual no implica mejora en la voluntad de verdad. La prueba es que no se corren riesgos -lo cual remite a una voluntad-, por decir la verdad - lo cual remite a la realidad.

En la tradición bíblica, "decir verdad" es un imperativo que viene de lejos. Y de lejos también viene cuán peligroso es el ámbito en el que se mueve la verdad. "El maligno es asesino y mentiroso", dice el evangelio de Juan $(8,44)$. Primero da muerte y después la encubre. Mons. Romero fue consciente de ello. Y además, en consonancia con Puebla, vio que la finalidad última del decir verdad consistía en "defender al pobre".

Desde estas convicciones, Mons. Romero dijo la verdad de forma nunca antes conocida en el país. La dijo vigorosamente, pues se remitía a lo fundamental: "nada hay tan importante como la vida humana. Sobre todo, la persona de los pobres y oprimidos" (16 de marzo de 1980). Dijo la verdad extensamente, para poder decir "toda la verdad". Y la dijo públicamente "desde los tejados", como Digitalizado por Biblioteca "P. Florentino Idoate, S.J." Universidad Centroamericana "José Simeón Cañas" 
pedía Jesús, en la catedral y a través de la YSAX. Dijo la verdad popularmente, aprendiendo muchas cosas del pueblo, de modo que, sin saberlo, los pobres y los campesinos eran coautores de sus homilías y cartas pastorales. "Entre ustedes y yo, hacemos esta homilía" (16 de septiembre de 1979). Y fue también popular en un doble sentido. Respetó y apreció la "razón", el discurrir del pueblo, de la gente sencilla. Y a la vez, evitó, con éxito, los intentos de infantilización, tentación normal en los discursos políticos, muchas veces en la pastoral, e incluso en el trasfondo de las actividades académicas.

En momentos cumbres, dijo la verdad solemnemente. "Esto es el imperio del infierno" (1 de julio de 1979), denunció. "Sobre estas ruinas, brillará la gloria del Señor" (7 de enero de 1979), consoló y dio esperanza. "En nombre de Dios, pues, y en nombre de este sufrido pueblo, cuyos lamentos suben hasta el cielo cada día más tumultuosos, les suplico, les ruego, les ordeno, en nombre de Dios: ;cese la represión!" (23 de marzo de 1980). Fue lo absolutamente inesperado, tanto para amigos como para enemigos.

Su modo de "decir la verdad" lo llevó a ser pionero de lo que ahora se llama "la memoria histórica". No es invento de ahora. A Monseñor le surgió connaturalmente. Hablaba con precisión escrupulosa, con el mejor sprit de géométrie, de Pascal, mencionando todos y cada uno de los nombres de las víctimas, de los familiares abandonados, de los victimarios, el lugar y el tiempo, las circunstancias. Y lo hacía con total delicadeza y lleno de dolor. "Se me horrorizó el corazón cuando vi a la esposa con sus nueve niñitos pequeños, que venía a informarme. Según ella, lo encontraron [al esposo] con señales de tortura y muerte. Ahí está esa esposa con esos niños desamparados... Es necesario que tantos hogares que han quedado desamparados, como este, reciban la ayuda. El criminal que desampara un hogar tiene obligación en conciencia de ayudar a sostener ese hogar" (20 de noviembre de 1977). Es el sprit de finesse del que debe estar empapada toda memoria histórica.

Y también hizo realidad la memoria histórica, más olvidada hoy en día, el recuerdo de la bondad, la entrega, la esperanza y la confianza en Dios de muchos mártires. Muchos de ellos matados por la justicia, inocente, indefensa, masiva y cruelmente. No le preocupó mucho, pienso que nada, que Roma lo reconociese, si llegara a haber beatificaciones y canonizaciones. Al hablar de ellos, Monseñor agradeció su vida y su muerte. Así los mantuvo vivos.

Al decir verdad, como Jesús, Monseñor habló "como quien tiene autoridad, no como los letrados". "La gente quedaba asombrada de su doctrina". La autoridad no le venía, como tampoco a Jesús, de su origen: "¿De Nazaret - de Ciudad Barrios-, puede salir cosa buena?". Ni tampoco de su condición de obispo, pues en su tiempo -y desgraciadamente, después-, varios obispos del país no eran nada respetados por las torpezas que decían y cometían. A Digitalizado por Biblioteca "P. Florentino Idoate, S.J." 
Monseñor, la autoridad no le venía de añadidos categoriales convencionales -títulos, autoridad jerárquica...-, sino de cosas reales: su autenticidad y convicción, expresadas en su honradez con lo real y en su coherencia entre decir y hacer. Monseñor crecía y se desbordaba en su hacer justicia y en su amor al pueblo. Y creció cada vez más en correr riesgos por defenderlo, muy consciente de lo que le podía ocurrir. Y que ocurrió.

Decir la verdad significó también "desenmascarar" lo que se encubre, condenar los cosméticos con los que, hipócritamente, se maquilla la violación de los mandamientos de la ley de Dios: no depredar, no acaparar y no matar, cuando es necesario para depredar y acaparar. Monseñor mantuvo viva la exigencia total, sine qua non, del octavo mandamiento: no mentir. $\mathrm{Y}$ al decir la verdad, hacía presente "la ira de Dios [que] se revela contra toda clase de hombres impíos e injustos que aprisionan la verdad con su injusticia" (Rom 1,18).

Monseñor dejó sin maquillaje y desenmascaró la riqueza. "Yo denuncio, sobre todo, la absolutización de la riqueza, ese es el gran mal de El Salvador: la riqueza, la propiedad privada, como un absoluto intocable. ¡Y ay del que toque ese alambre de alta tensión! Se quema" (12 de agosto de 1979). Desenmascaró la violación del séptimo mandamiento, el pecado originante.

Sus mayores diatribas fueron contra la muerte injusta y cruel. "No me cansaré de denunciar el atropello por capturas arbitrarias, por desaparecimientos, por torturas" (24 de junio de 1979). "La violencia, el asesinato, la tortura, donde se quedan tantos muertos, el machetear y tirar al mar, el botar gente: esto es el imperio del infierno" (1 de julio de 1979). Desenmascaró la violación del quinto mandamiento, cuando esta es necesaria para depredar o mantener lo depredado.

Clamó contra los medios de comunicación y los discursos oficiales. "Falta, en nuestro ambiente, la verdad" (12 de abril de 1979). "Sobra quienes tienen su pluma pagada y su palabra vendida" (18 de febrero de 1979). "Estamos en un mundo de mentiras, donde nadie cree ya en nada" (19 de marzo de 1979). Desenmascaró la violación del octavo mandamiento, lo que ocurre para encubrir la violación de los dos anteriores. $\mathrm{Y}$ es que escándalo y encubrimiento son correlativos.

Hagamos una pausa reflexiva. En el epígrafe, hemos recordado las palabras de Pedro sobre Jesús, "pasó haciendo el bien". Y en el sentido preciso de hacer el bien, hemos analizado las palabras del campesino, Monseñor dijo la verdad. Debiera ser evidente que decir la verdad es hacer el bien. Pero la realidad puede llegar a ser tal, que decir la verdad puede ser hacer el mayor y el más necesario de los bienes. Eso es lo que ocurrió el 23 de marzo de 1980, víspera de su asesinato. Juzgue el lector si al decir verdad, Mons. Romero no pasó haciendo el máximo bien. 
Yo quisiera hacer un llamamiento de manera especial a los hombres del ejército, y en concreto a las bases de la Guardia Nacional, de la Policía, de los cuarteles.

Hermanos, son de nuestro mismo pueblo, matan a sus mismos hermanos campesinos, $\mathrm{y}$, ante una orden de matar que dé un hombre, debe prevalecer la ley de Dios que dice: "No matar"*. Ningún soldado está obligado a obedecer una orden contra la ley de Dios*. Una ley inmoral, nadie tiene que cumplirla*. Ya es tiempo de que recuperen su conciencia y que obedezcan antes a su conciencia que a la orden del pecado*. La Iglesia, defensora de los derechos de Dios, de la ley de Dios, de la dignidad humana, de la persona, no puede quedarse callada ante tanta abominación. Queremos que el gobierno tome en serio que de nada sirven las reformas si van teñidas con tanta sangre*.

En nombre de Dios, pues, y en nombre de este sufrido pueblo, cuyos lamentos suben hasta el cielo cada vez más tumultuosos, les suplico, les ruego, les ordeno, en nombre de Dios: ¡cese la represión!*** (Los asteriscos expresan los aplausos con que la gente respondía a sus palabras en la catedral).

Y antes de terminar la homilía con esas palabras, con espanto, ante la realidad del país, y con claros presagios sobre su propio asesinato, sereno y conmovido, explicó al mundo cómo preparaba la homilía del domingo. "Le pido al Señor, durante la semana, mientras voy recogiendo el clamor del pueblo y el dolor de tanto crimen, la ignominia de tanta violencia, que me dé la palabra oportuna para consolar, para denunciar, para llamar al arrepentimiento" (23 de marzo de 1980).

Monseñor dijo la verdad porque se le removieron las entrañas - la misericordia que insistentemente nos recuerda el papa Francisco. Y en ello puso toda su vida en juego, como veremos a continuación. Eso fue, para Monseñor, "pasar haciendo el bien".

\section{2. "Monseñor nos defendió a nosotros, de pobres"}

Así siguió el campesino. Quiero recordar que Puebla había hablado de la opción por los pobres, pero con una precisión que no suele ser tenida muy en cuenta. Dijo que "por el solo hecho de ser pobres, Dios los defiende y los ama". La opción por los pobres no consiste, entonces, solo en amar a los pobres ayudarlos, cuidar de ellos de mil maneras, sino ante todo, en "defenderlos". Es lo que intuitivamente captó el campesino, y habló con precisión. "Monseñor nos defendió a nosotros, de pobres". No tengo nada que añadir a esta solemne sentencia del campesino. Ni al lenguaje que usó: nos defendió a nosotros, "de pobres", es decir, "por ser pobres". Solo voy a intentar mostrar cómo defendió Monseñor a los pobres y oprimidos del país.

Monseñor defendió la organización popular para defender los derechos de

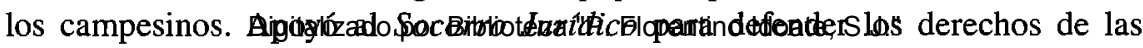
Universidad Centroamericana "José Simeón Cañas" 
víctimas. Cuando arreció la represión, abrió las puertas del seminario San José de la Montaña para acoger a los campesinos que huían de Chalatenango, lo que sorprendió y disgustó a muchos jerarcas. Y ciertamente, defendió a los pobres con la verdad que proclamaba públicamente en sus homilías.

Pero hay que estar claros. Defender supone enfrentarse con los que agreden, empobrecen, oprimen y reprimen. Por defender a los pobres, Monseñor se enfrentó con los que mienten y asesinan, ya fuesen personas, instituciones o estructuras. Y la suya fue una defensa primordial, que iba más allá de lo que convencionalmente se entiende por "defender y ganar un caso". No fue ese su horizonte, sino que quería que ganase la realidad maltrecha, que triunfaran la justicia y la verdad.

Este es el contexto de su célebre denuncia de la Corte Suprema de Justicia. Esta lo había emplazado públicamente para que dijese los nombres de "los jueces que se venden", a los que Monseñor habría denunciado en su homilía dominical. Los asesores de Monseñor estaban asustados y no sabían cómo iba a salir con bien ante tal emplazamiento. Monseñor no se alteró. En la homilía siguiente, aclaró, en primer lugar, que él no había dicho "jueces que se venden", sino "jueces venales". Y sin más miramientos, fue al fondo de la cuestión.

¿Qué hace la Corte Suprema de Justicia? ¿Dónde está el papel trascendental en una democracia, de este poder que debía estar por encima de todos los poderes y reclamar justicia a todo aquel que la atropella? Yo creo que gran parte del malestar de nuestra patria tiene allí su clave principal, en el presidente y en todos los colaboradores de la Corte Suprema de Justicia, que con más entereza deberían exigir a las cámaras, a los juzgados, a los jueces, a todos los administradores de esta palabra sacrosanta, la justicia, que de verdad sean agentes de justicia (30 de abril de 1978).

Al llegar a este punto, permítaseme un paréntesis, que puede concernir a iglesias y universidades, por mencionar dos instituciones que nos atañen. Deben "hacer el bien", pero no solo ayudando al pobre, sino defendiéndolo de sus agresores. Y deben defenderlo no solo en uno u otro ámbito de sus problemas, sino en totalidad $-\mathrm{y}$ ciertamente, debe hacerlo una universidad que sea universitas, abierta por principio a la totalidad. Importantes y necesarios son los institutos de derechos humanos, pero no bastan; el derecho debe defenderlos. La economía debe defender del hambre y combatir a quienes, personas o estructuras, la producen, y más, cuando la pobreza es consecuencia de un sistema de producir riqueza. Lo mismo se puede decir de las ingenierías y de su capacidad para producir espacios vivibles o inhumanos. De las psicologías, que orientan o desorientan ante lo que ocurre con la salud mental, personal, y sobre todo, social. De lla medicina, la sociología, la política, la historia, la literatura, la filosofía. Y de la teología: cómo llegar a conocer y pensar a un Dios en favor de y defensor Digitalizado por Biblioteca "P. Florentino Idoate, S.J."

Universidad Centroamericana "José Simeón Cañas" 
de la vida de los pobres, cómo caminar con Él, humildemente en la historia, y cómo practicar a Dios, como dice Gustavo Gutiérrez.

Creo que Monseñor fue defensor del pobre, movido por total humanidad. Cinco días antes de ser asesinado, a un periodista extranjero que le preguntaba cómo ser solidarios con el pueblo salvadoreño, le contestó: "El que no pueda hacer otra cosa, que rece. $Y$ no olviden que somos hombres... Y que aquí están sufriendo, muriendo, huyendo, refugiándose en las montañas". Y seis semanas antes de ser asesinado, en Lovaina, con gran naturalidad, elevó lo humano empobrecido y agredido a realidad teologal. Introdujo al pobre en el ámbito de Dios: "la gloria de Dios es que el pobre viva".

\section{3. "Y por eso, lo mataron"}

Estas palabras no necesitan comentario. El mismo Monseñor dijo que "se mata a quien estorba". Por aquellos años, en 1975, la Congregación General XXXII de la Compañía de Jesús había pedido a los jesuitas "introducirse en la lucha crucial de nuestro tiempo, la lucha por la fe y la lucha por la justicia que esta misma exige". Y los padres reunidos en la congregación añadieron sabiamente: "no lo haremos sin pagar un precio". Desde entonces, el número de jesuitas asesinados por luchar contra la injusticia ha sido alrededor de 60. Según lo que acabamos de decir, "se mata al que defiende al oprimido".

En el retiro que hizo un mes antes de su asesinato, Mons. Romero le confió al padre Azkue los tres temores que más lo afligían. Uno, debido más bien a su talante escrupuloso, era si llevaba bien su vida espiritual. Otro, que le hizo sufrir mucho, su gran dificultad para trabajar con sus hermanos obispos. Y el que ahora nos interesa, "el miedo a una muerte violenta".

De hecho, Monseñor vivió tres años de muerte anunciada. Estallaron bombas en templos, en el seminario, en residencias de religiosos y religiosas, en colegios católicos, en la UCA. Hubo atentados en instrumentos de trabajo de la arquidiócesis, la imprenta, la YSAX. Especialmente dolorosos y premonitorios tuvieron que ser los asesinatos de seis sacerdotes, un jesuita y cinco diocesanos. Su muerte estaba anunciada.

También, durante tres años, tuvo que vivir con el odio de los poderosos. No le perdonaban, y no se arrepentían, ni del daño que hacían a los pobres, ni del odio que le tenían a Monseñor. A treinta y siete años de su muerte, no sé cuántos le han pedido perdón. Sé que algunos sí lo han hecho.

Mons. Ricardo Urioste, su vicario general, recientemente fallecido, ha repetido que "Monseñor Romero fue el salvadoreño más querido y el más odiado". Es claro que ha sido el más querido, quien ha proporcionado alegría y dignidad al pueblo. $Y$ es claro que lo odiaron mucho y muchos: potentados, 
opresores y victimarios, escuadrones de la muerte, militares y cuerpos de seguridad, gobernantes y políticos - los de casa y los del imperio del norte-, muchos medios de comunicación y algunos miembros de la jerarquía, aquí y en Roma.

Pero Monseñor no devolvió mal por mal, y nunca odió a quienes lo odiaban. La razón no era la ascesis, sino no poder ser de otra manera. Muy poco antes de su muerte, dijo, en la homilía del 16 de marzo: "Me da más lástima que cólera, cuando me ofenden y me calumnian [...] Que sepan que no guardo ningún rencor, ningún resentimiento". Monseñor pudo cargar con el odio contra él porque cargó con el sufrimiento de los pobres, los oprimidos, las víctimas, y ellos cargaron con él. Quien ama y es amado así, no puede odiar a nadie. Solo puede amar a todos.

No sé qué pensará el campesino de estas reflexiones. Pero, para conocer a Mons. Romero, me gusta repetir sus palabras: "Monseñor dijo la verdad, nos defendió a nosotros, de pobres. Y por eso, lo mataron".

\section{2. “Con Monseñor Romero, Dios pasó por El Salvador"}

También Ellacuría vio que Monseñor "pasó haciendo el bien". En varias ocasiones, dijo en detalle los bienes que hacía. Y concluyó de manera, si no idéntica, sí afín a la de Pedro ante Cornelio: "Dios estaba con él".

Sus palabras pueden sorprender, o asustar, pero para quien conoció a Ellacuría, no es pensable que hablase a la ligera de Monseñor Romero y menos de Dios. A Ellacuría se le hizo cada vez más difícil hablar de Mons. Romero sin verse forzado a hablar de Dios, así como una vez afirmó que era "difícil hablar de Mons. Romero, sin hablar del pueblo".

Pedro, en casa de Cornelio, dijo que Dios estaba con Jesús. Ellacuría dijo que Dios pasó con Monseñor. Para entender o intuir lo que quería decir Ellacuría, me remitiré a tres textos suyos, que mencionamos en orden teológico, más que cronológico. En ellos, Ellacuría habla solemne y teologalmente de Mons. Romero.

El primer texto es de los inicios del ministerio arzobispal de Monseñor. El segundo, de pocos meses después de su asesinato. El tercero, y más radical, de la misa del funeral de Monseñor en la UCA. En cada uno de ellos, aparece una afirmación teologal breve y lapidaria sobre la relación que podemos llamar funcional-real entre Mons. Romero y Dios, a lo cual añade algunas afirmaciones explicativas de las muchas y variadas realidades históricas que llevó a cabo Monseñor, en las que Ellacuría encontró fundamento para las afirmaciones teologales. De esto no vamos a hablar ahora. Remito a mi artículo "El impacto de Monseñor Romero en Ignacio Ellacuría", Revista Latinoamericana de Teología, 90 (2013), 195-212. Veamos las afirmaciones teologales. 
- "He visto en la acción de usted el dedo de Dios" (p. 198). "Desde este lejano exilio quiero mostrarle mi admiración y respeto", comienza Ellacuría la carta que escribió a Monseñor, el 9 de abril de 1977, desde Madrid, a propósito de su reacción tras el asesinato del padre Rutilio Grande, el 12 de marzo de ese año. Y continúa: "he visto en la acción de usted el dedo de Dios". Es la afirmación teologal. Y añade tres razones explicativas para que la expresión no quedara reducida a acompañamiento meramente literario.

- "Monseñor Romero, un enviado de Dios para salvar a su pueblo" (p. 200). Tras el martirio de Monseñor, la revista Sal Terrae pidió a Ellacuría, en noviembre de 1980, que escribiese un artículo sobre Mons. Romero. Así lo hizo y publicó un texto con el título "Monseñor Romero, un enviado de Dios para salvar a su pueblo". La afirmación teologal es "Monseñor Romero, un enviado de Dios". Y añade la explicación de lo que él entiende por la salvación llevada a cabo por Monseñor, tema este sumamente importante para Ellacuría.

- "Con Monseñor Romero, Dios pasó por El Salvador" (p. 202). El pensamiento de Ellacuría sobre Monseñor alcanzó su punto culminante en esta formulación de la homilía que pronunció en el funeral de la UCA, pocos días después del asesinato: "Con Monseñor Romero, Dios pasó por El Salvador".

En estas palabras hay genialidad de pensamiento, y no conozco pastores, ni teólogos, ni miembros de la Congregación de las Causas de los Santos, responsables de la beatificación de Romero, que hayan conceptualizado y formulado las cosas con tal radicalidad, y que se hayan esmerado en fundamentarlas como lo hizo Ellacuría. Las palabras pueden extrañar y sorprender a creyentes, y ciertamente, a no creyentes. Pudieran parecer poco científicas y poco académicas, y, aunque teologales, quizás no suenen en exceso piadosas. Para mí, tienen una gran verdad y son fructíferas. Al menos, expresan más verdad y producen mejores frutos que otras palabras que he escuchado sobre Mons. Romero. Me explico.

En Mons. Romero, Ellacuría vio a un ser humano, en quien se hacía presente la realidad con tal ultimidad y radicalidad, que, en ese grado, no lo encontró en ninguna otra persona. $\mathrm{Ni}$ análogamente, en ninguna realidad social, aunque fuesen cosas buenas, como la verdad y la libertad, la democracia y el socialismo, en estado de autenticidad. Eso último y radical es lo que captó Ellacuría y afloró en la persona de Monseñor, y sin que Ellacuría hablase así, que yo recuerde, de otras personas del pasado, ni siquiera de personas sumamente apreciadas. Para Ellacuría, Mons. Romero fue realmente, como Jesús, sacramento de Dios.

\section{Nuestro seguimiento de Mons. Romero}

Nuestro seguimiento es lo más importante que puede desprenderse de las conmemoraciones y celebraciones de Monseñor. Por eso, quiero terminar con dos

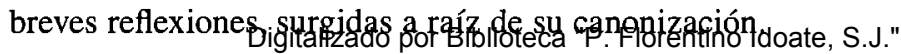

Universidad Centroamericana "José Simeón Cañas" 
La primera es una reflexión sobre si Mons. Romero fue un mártir de la fe o de la justicia, pregunta que no tiene relevancia para su seguimiento. Está claro que Monseñor fue matado, y así empezamos por lo evidente. Monseñor murió matado, y lo mataron y fue matado porque estorbó. En el país, no estorbó su fe personal en un Dios trascendente, que la tuvo, sino su enfrentamiento con criminales que quitaban la vida a inocentes. Defender al inocente fue la causa de morir asesinado. Corresponde a la Congregación de las Causas de los Santos decidir si, canónicamente, eso convierte a Mons. Romero en un mártir de la fe o en mártir de la justicia. No hay que olvidar que Monseñor, antes que mártir - testigo, como suele enfatizarse-, fue víctima. Y como tal, ya está inscrito en el libro de las víctimas, de esa innumerable nube de salvadoreños y salvadoreñas. Otras cosas se podrán olvidar, pero no esta.

La otra reflexión es a propósito de los milagros necesarios para la canonización. ¿Se necesitan milagros? ¿Cuántos? ¿Tiene poder el papa para canonizar "por equivalencias"? Y sobre todo, ¿qué es un milagro? Una noción de milagro, la más tradicional en el contexto de las canonizaciones, es la aparición de un poder capaz de actuar en contra de, o más allá de, las leyes de la naturaleza, lo cual solo puede ser única y exclusivamente obra de Dios. En la Biblia no aparece tal noción, y en el presente, al seguidor de Jesús lo deja indiferente. Otra noción es la aparición de un gran amor, capaz de convertirnos y de hacernos mejores. Y ahí hemos visto la presencia de Dios. En este sentido, Mons. Romero ha sido él mismo un milagro, desde el 12 de marzo de 1977, día en que asesinaron a Rutilio Grande, y lo sigue siendo hasta el día de hoy. La canonización queda para la burocracia.

¿No sería posible, por una sola vez, que la causa de los santos no nos meta en estos atolladeros? ¿No bastará estar de acuerdo con don Pedro Casaldáliga, cuando dice que "nuestra coherencia será la mejor canonización de 'San Romero de América, Pastor y Mártir"'? ¿No bastará alegrarnos de que con Mons. Romero, Dios pasó por El Salvador? ¿No será lo mejor buscar, agradecer y abrazar a nuestro campesino?

$$
* * *
$$

\section{Carta de Ignacio Ellacuría a Monseñor Romero \\ Madrid, \\ 9 de abril de 1977.}

Querido Monseñor:

He podido seguir muy de cerca y con abundante información los gloriosos acontecimientos - muerte y resurrección- que han ocurrido especialmente

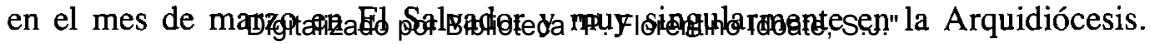


Así he sabido de sus intervenciones como arzobispo de San Salvador. Dios ha querido ponerle al comienzo mismo de su ministerio en un trance sumamente difícil, sumamente cristiano, porque si en él ha sobreabundado el delito, más ha sobreabundado la gracia. Tengo que expresarle, desde mi modesta condición de cristiano y sacerdote de su arquidiócesis, que me siento orgulloso de su actuación como pastor. Desde este lejano exilio quiero mostrarle mi admiración y respeto, porque he visto en la acción de usted el dedo de Dios. No puedo negar que su comportamiento ha superado todas mis expectativas y esto me ha producido una profunda alegría, que quiero comunicársela en este sábado de gloria.

Permítame que, dada mi condición de estudioso de la teología, le razone un poco los motivos de mi orgullo, admiración y respeto. Yo creo que el martirio del Padre Grande y de los demás cristianos ha merecido para El Salvador una ejemplaridad singular para toda la Iglesia Latinoamericana. No sé en qué otra parte hubieran podido estar a tanta altura los sacerdotes y sus pastores.

El primer aspecto que me ha impresionado es el de su espíritu evangélico. Lo supe desde el primer instante por comunicación del P. Arrupe. Son muchos los pastores que alardean de espíritu evangélico, pero que, puestos en la prueba de fuego -y lo hemos visto en el propio San Salvador-, muestran que no hay tal espíritu. Usted inmediatamente percibió el significado limpio de la muerte del Padre Grande, el significado de la persecución religiosa, y respaldó con todas sus fuerzas ese significado. Eso muestra su fe sincera y su discernimiento cristiano. Muestra también su valentía y su prudencia evangélicas frente a claras cobardías y prudencias mundanas. Es muy difícil que en casos como este el evangelio esté de parte de la ANEP, del Gobierno; usted lo vio claramente y con independencia y firmeza sacó sus conclusiones y tomó sus decisiones.

Esto me hace ver un segundo aspecto: el de un claro discernimiento cristiano. Usted, que conoce los Ejercicios de san Ignacio, sabe lo difícil que es discernir y decidir según el espíritu de Cristo y no según el espíritu del mundo, que se puede presentar sub angelo lucis. Tuvo el acierto de oír a todos, pero acabó decidiendo por lo que parecía a ojos prudentes lo más arriesgado. En el caso de la única misa, de la supresión de las actividades de los colegios, de su firme separación de todo acto oficial, etc., supo discernir dónde estaba la voluntad de Dios y supo seguir el ejemplo y el espíritu de Jesús de Nazaret. Esto me ha dado a mí grandes esperanzas de que su ministerio, que ha de ser muy difícil, pueda seguir siendo plenamente cristiano en unos momentos de América Latina, donde tan difícil se presenta la verdadera vida de la Iglesia, más que nunca llamada a ser una vida de testimonio y de martirio.

El tercer aspecto lo veo como una conclusión de los anteriores y como su comprobación. En esta ocasión y apoyado en el martirio del Padre Grande. Usted ha hecho Iglesia y ha hecho unidad en la Iglesia. Bien sabe usted lo difícil que

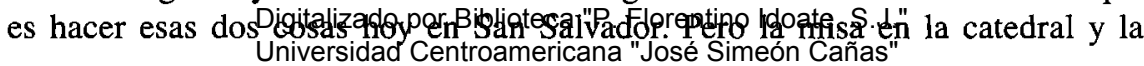


participación casi total y unánime de todo el presbiterio, de los religiosos y de tanto pueblo de Dios muestran que en esa ocasión se ha logrado. No ha podido entrar usted con mejor pie a hacer Iglesia y a hacer unidad en la Iglesia dentro de la arquidiócesis. No se le escapará que esto era difícil. Y usted lo ha logrado. Y lo ha logrado no por los caminos del halago o del disimulo, sino por el camino del evangelio: siendo fiel a él y siendo valiente con él. Pienso que mientras usted siga en esta línea y tenga como primer criterio el espíritu de Cristo martirialmente vivido, lo mejor de la Iglesia en San Salvador estará con usted y se le separarán quienes se le tienen que separar.

En la hora de la prueba se puede ver quiénes son fieles hijos de la Iglesia, continuadora de la vida y de la misión de Jesús, y quiénes son los que se quieren servir de ella. Me parece que en esto tenemos un ejemplo en la vida última del Padre Grande, alejada de los extremismos de la izquierda, pero mucho más alejada de la opresión y de los halagos de la riqueza injusta, que dice san Lucas.

Finalmente, creo que esta dolorosa y gozosa ocasión le habrá dado oportunidad para reencontrar a la verdadera Compañía de Jesús, de la que gentes interesadas le han querido apartar. Según he podido escuchar y leer, usted se ha entregado a la Compañía y la Compañía se ha entregado a usted. Habrá visto que la Compañía en El Salvador quiere ser fiel a Cristo y a la Iglesia y lo quiere ser hasta las últimas consecuencias. No siempre es fácil y no siempre acertará. La Compañía está por vocación en la frontera, en el límite donde los peligros de toda índole son mayores. En ese terreno no es fácil acertar siempre ni en las ideas ni en las acciones. Pero yo pienso que hay en ella suficiente espíritu para reconocer sus errores y para no cejar en su empeño. Usted ha debido comprobar en esta hora difícil cuánta gente verdaderamente espiritual y verdaderamente capaz tiene la Compañía al servicio de Cristo y de la Iglesia en El Salvador.

Yo pido a Dios que todas estas cosas sigan para bien de todos. No ha sido más que el comienzo, pero ha sido un extraordinario comienzo. El Señor le ha deparado un principio extraordinariamente cristiano en su nuevo ministerio. Que Él le conceda seguir adelante entre tan excepcionales dificultades. Si logra mantener la unidad de su presbiterio mediante su máxima fidelidad al evangelio de Jesús, todo será posible.

Esto es lo que le desea de todo corazón este miembro de la arquidiócesis, que ahora se ve alejado contra toda su voluntad, pienso que por anunciar el evangelio. Le reitero mi admiración y mi agradecimiento por sus primeros pasos - que conozco muy bien en toda su complejidad-como arzobispo de San Salvador.

Afmo. en Cristo,

Ignacio Ellacuría 